\title{
A mulher de negócios no discurso do trabalho feminino
}

\author{
Cristiane Gomes de Souza ${ }^{1}$ \\ https://orcid.org/0000-0003-2658-3825 \\ ${ }^{1}$ Universidade Federal de Alagoas, Departamento de Letras e Linguística, Programa de Pós Graduação em Letras e Linguística, Maceió, \\ AL, Brasil
}

\begin{abstract}
A mulher de negócios no discurso do trabalho feminino
Resumo: Este texto discute sobre a mulher de negócios corporificada no desenvolvimento de suas práticas e premiações advindas do empreendedorismo feminino segundo a discursividade do SEBRAE. Para isto, analisa-se o movimento de (re)formulação do discurso do SEBRAE sobre a mulher para evidenciar os efeitos de sentido do discurso do capital. O objetivo é identificar a mulher de negócios no discurso do trabalho feminino como espaço constitutivo de convergência, divergência e silêncio entre essas mulheres. A pesquisa tomou como base os pressupostos teórico-metodológicos da Análise do Discurso (AD) de origem francesa, filiada a Pêcheux, e da Psicanálise. Defende-se que as relações interdiscursivas do SEBRAE sobre o empreendedorismo feminino contribuem, de forma ideológica e inconsciente, para a constituição de discursos hegemônicos que elegem o empreendedorismo feminino contemporâneo como único modelo possível de geração de riqueza, liberdade e desfaçatez do sofrimento da mulher.
\end{abstract}

Palavras-chave: Empreendedorismo. Mulher. Análise do Discurso. Psicanálise. Gênero.

\section{The businesswoman in female labor speech}

Abstract: This text discusses the corporate woman in the development of her practices and awards arising from female entrepreneurship according to the discourse of SEBRAE. For this, the movement of (re) formulating SEBRAE's discourse on women is analyzed in order to highlight the meaning effects of capital's discourse. The objective is to identify the business woman in the discourse of female work as a constitutive space of convergence, divergence and silence among these women. The research was based on the theoretical and methodological assumptions of Discourse Analysis (AD) of French origin, affiliated with Pêcheux, and of Psychoanalyses. It is argued that the interdisciplinary relations of SEBRAE on female entrepreneurship, contribute, in an ideological and unconscious way, to the constitution of hegemonic discourses that elect contemporary female entrepreneurship as the only possible model for generating wealth, freedom and boldness in the suffering of women Keywords: Entrepreneurship. Woman. Speech analysis. Psychoanalysis. Genre.

Recebido em 18.02.2020. Aprovado em 06.05.2020. Revisado em 08.06.2020.

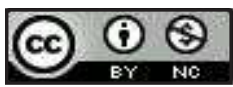

(C) O(s) Autor(es). 2020 Acesso Aberto Esta obra está licenciada sob os termos da Licença Creative Commons

Atribuição-NãoComercial 4.0 Internacional (https://creativecommons.org/licenses/by-nc/4.0/deed.pt_BR), que permite copiar, distribuir e reproduzir em qualquer meio, bem como adaptar, transformar e criar a partir deste material, desde que para fins não comerciais e que você forneça o devido crédito aos autores e a fonte, insira um link para a Licença Creative Commons e indique se mudanças foram feitas. 


\section{Introdução}

Convive-se com um período histórico particularmente difícil. As últimas décadas vêm sendo marcadas por profundas transformações do sistema capitalista mundial, acarretando muitos impactos na organização e nos processos do trabalho.

Discutir transformações na realidade em que se está imerso não constitui uma tarefa fácil. Isso porque formulações a esse respeito exigem um entendimento cuidadoso de mudanças ainda em curso, como também uma análise que vá além daquilo que é aparente, e que consiga estabelecer as relações das várias "partes" com o todo.

Neste artigo adoto como eixo norteador das análises as dimensões do sistema de capital, que são completamente articuladas: Trabalho e Capital. Na verdade, entendo que capital se articula e se constitui num processo metabólico de controle de todas as esferas da sociabilidade humana, de modo a analisar, criticamente, a condição social de nosso mundo contemporâneo. Especialmente, entender o desenho e os limites do discurso do trabalho e empreendedorismo feminino nessas conformações.

E, em se tratando das dimensões do sistema do capital, parece-me necessário apresentar inicialmente o entendimento sobre o trabalho em Marx. Nessa perspectiva, o trabalho aparece como categoria fundante do mundo dos homens. E tem, então, uma dimensão ontológica porque ele está enraizado na existência dos homens, de tal maneira que sem ele nem homens e nem história poderiam existir. Ou seja, é o mesmo que dizer que o trabalho tem um caráter de anterioridade, isto é, ele é anterior e determinante das variadas formas dos homens existirem e se organizarem socialmente.

Esses estudos me levaram sempre a uma inquietação, sobretudo, a buscar uma interlocução com a Psicanálise por conta da concepção de sujeito, noção que é central em ambos os campos teóricos (Análise do Discurso e Materialismo Histórico), e que apresenta particularidades e afinidades mútuas instigantes. Especialmente porque o assunto em tela põe à luz o tema da mulher na época em que se vive.

A minha inquietação sobre a mulher como objeto de pesquisa iniciou na década de 2000, quando comecei a desenvolver atividades como consultora do SEBRAE, e, como aluna de mestrado, em 2006, quando tive o primeiro contato com a Teoria do Discurso. Nessa mesma década, todavia, escolhi começar pelos estudos sobre o Trabalho e Educação, no mestrado ${ }^{1}$, mas já voltada a estudar o discurso e suas condições de produção. Somente em 2015, prossegui com a escolha do discurso do empreendedorismo como objeto, após lidar com mulheres que abriam suas empresas com o "apoio" do SEBRAE, mas também como avaliadora do Prêmio SEBRAE "Mulher" de Negócios (PSMN).

Diante desses fundamentos, coube a mim analisar como o discurso, por exemplo do SEBRAE, é meio difusor de ideologia dominante. Como ela procura normalizar sentidos, homogeneizar comportamentos, relacionar mulheres às mercadorias, de modo tal que ao adquirir os serviços por ele anunciados, as mulheres adquiram também "poder" despertado por eles, e até possam romper e alcançar a sua emancipação como proprietária de bens.

O corpo teórico da Análise do Discurso oferece elementos conceituais que permitem estabelecer as conexões entre o objeto (o discurso) e o real efetivo em que se constitui. Busca-se neste campo de conhecimento o entendimento da essencialidade constitutiva do objeto e não apenas da sua aparente forma, marcada pelos fenômenos linguísticos. Nessa esfera de saber tornou-se indispensável o conhecimento da ideologia como função social representada no e pelo discurso.

\section{Desenvolvimento}

As condições sociais encontradas historicamente no meio societal são dadas pelo trabalho. Fundamentadas e realizadas no trabalho. $\mathrm{O}$ trabalho, portanto, como a capacidade de produzir e criar as coisas é que humaniza o homem. O homem se faz homem ao relacionar-se com a natureza e com os outros homens por meio do trabalho. Nesse sentido, Marx reflete que:

[...] O trabalho é uma condição natural eterna da existência humana. O processo de trabalho não é mais do que o próprio trabalho, considerado no momento da atividade criadora. Os elementos gerais do processo de trabalho, por conseguinte, são independentes de todo e qualquer desenvolvimento social determinado. Os meios e materiais de trabalho, uma parte dos quais é produto de trabalhos precedentes, desempenham o seu papel em qualquer processo de trabalho, em qualquer época e em todas as circunstâncias [...]. (MARX, 2004, p. 64-65).

Como podemos ver, o homem é um ser histórico, portanto, sujeito de sua história. O pressuposto da existência humana é o trabalho. Essa condição humana é mediada entre o homem e a natureza pelo trabalho. $\mathrm{O}$ trabalho, pois, é a chave para a compreensão do homem, que necessita cotidianamente realizá-lo para poder viver. 
O discurso, enquanto produto da consciência - "consciência jamais pode ser outra coisa do que o ser consciente, e o ser dos homens é o seu processo de vida real" (MARX, 1986, p. 37) -, é definido em relação às particularidades de uma dada formação social. O discurso é, pois, uma particularidade, um campo de mediações que possibilita o acesso à realidade objetiva consubstanciada pelo entrelaçamento da singularidade com a universalidade.

Nesse sentido, compreende-se também o discurso como produto de um processo de relações entre indivíduos; é o resultado de um amplo e complexo trabalho interindividual "expresso" de forma oral ou escrita por uma singularidade (CHASIN, 1987, p. 66), que pode ser um indivíduo ou um grupo social.

O discurso é, pois, a forma mais complexa da linguagem da qual se valem as formações ideológicas para orientar, controlar e dominar a sociedade em desenvolvimento, em função das ideias dominantes da classe dominante da época. Como diz Marx (1986, p. 72): "As ideias da classe dominante são, em cada época, as ideias dominantes; isto é, a classe que é a força material dominante da sociedade é, ao mesmo tempo, sua força espiritual dominante".

Para Amaral (2017), há uma multiplicidade de sentidos produzidos no movimento discursivo em que o trabalho é o objeto. Assim, na teoria social marxiana, o trabalho é um discurso fundador da sociabilidade. Na sociedade capitalista, o sentido ontológico de trabalho, da esfera determinante do ser social, desloca-se para o sentido burguês: "é degradado a um estratagema de exploração por meio do domínio da propriedade capitalista" (KURZ, 1997, p. 272). E, assim, o trabalho se constitui em ideal burguês que responde ao processo de acumulação de riqueza.

Essas funções do discurso trabalho são particularidades do trabalho na sociedade de classes condicionadas pela divisão do trabalho - propriamente dita quando "surge uma divisão entre o trabalho material e o espiritual" (MARX, 1986, p. 45) -, divisão entre quem produz, os trabalhadores, e os que detêm os meios de produção, os proprietários capitalistas. O discurso trabalho na sociedade moderna - sob a dominação da classe burguesa - silencia essas funções, principalmente a de disciplina, e constrói evidências de uma política de ganho e produtividade a partir das adesões ditas "voluntárias" dos sujeitos "livres", que, paradoxalmente, funcionam em relações de dependência.

\section{O discurso feminino}

O discurso do empreendedorismo feminino, no Brasil, tornou-se lugar comum nos estudos nas primeiras décadas do século XX, no final dos anos 1990, atravessado por propostas que demandam análises mais acuradas para entender como as mulheres são estimuladas, especialmente pelo Serviço Brasileiro de Apoio às Micro e Pequenas Empresas (SEBRAE), para que desenvolvam atitudes de enfrentamento dos desafios atuais, principalmente no que diz respeito aos negócios.

Dessa maneira, o discurso das mulheres que empreendem se estabelece de maneira contraditória, dada a sua constituição histórica, em que se questionam discursos oponentes em razão das conformidades ${ }^{2}$ pelas quais a mulher passa. Tais conformidades são expressas na divisão sexual do trabalho, nas determinações materiais da (re)produção do capital, que estabelecem uma organização social desigual e hierárquica, em consonância com o princípio antagonista que estrutura a sociedade capitalista.

Nesse contexto, pergunta-se a quem pertence, afinal, o trabalho feminino? E mesmo sabendo que a alienação é comum a ambos os sexos, há implicações particulares no que tange às funções masculinas e femininas reverberando em desigualdades de gênero. Ao acrescentar, aqui, a pergunta feita por Freud: "O que quer a mulher?", reitera-se, sobretudo, nos dias de hoje, o mal-estar referente aos impasses colocados pelas escolhas e desejos femininos, que extrapolam o ideal materno. De fato, o que se pretende é referir a "mulher" de negócios (no discurso do SEBRAE), que exerce também trabalho não remunerado na ordem da reprodução social, num sistema patriarcal e capitalista, invisível, no ambiente doméstico, que favorece, principalmente, ao homem que ocupe o espaço público.

Considerando esses aspectos, ao se buscar trabalhar com o discurso do empreendedorismo feminino, é necessário levar em conta as condições de produção desse discurso em sentido estrito, considerando o contexto imediato, sobretudo em sentido amplo, incluindo o contexto sócio histórico e ideológico, assim como expõe Orlandi (2005).

\section{A mulher de negócios no discurso do SEBRAE}

A mulher contemporânea é significada no discurso do SEBRAE, conforme imagem elaborada em alusão a 8 de março, Dia Internacional da Mulher, retratada uma mulher que ocupa uma página formando um único 
cenário. O cenário revela o desenho de uma mulher de cabelos longos, sentada numa cadeira, pernas cruzadas, com expressão de seriedade, sofisticação e elegância, traços finos, remetendo à imagem da "moça comportada", bem-sucedida, conjugada à delicadeza atribuída socialmente ao sexo feminino, aproximando-a do estereótipo da "mulher perfeita", que merece flores (cores vermelhas) que realçam o desenho em preto e branco, ratificando como o grande Outro a faz mulher colocando-a no lugar de conveniência, comportada e funcional.

Num primeiro momento, a compreensão é de que a "mulher" de negócios ganha flores ao não esconder seus diferenciais. Todavia, a conotação pode ser outra: a mulher "em forma de rabisco", como uma performance feminina no mundo dos negócios reforça a concepção de um mundo tradicionalmente masculino, especialmente porque apresenta a imagem da executiva, que se relaciona à figura masculina, mais sóbria e discreta. Ter essa aparência, nesse caso, supostamente, diminui a respeitabilidade da mulher como profissional e faz parecer que qualquer sucesso não vem da sua capacidade, mas de autorizações concedidas (pelo SEBRAE) que, ao lhe dar flores, parece confirmar a fragilidade de uma rosa-mulher, ou melhor, a mensagem parece estar dialogando com o público masculino.

A cena traduzida numa arte a lápis, em folha quadriculada que é utilizada, geralmente, para desenhos e escritas de engenheiros, acompanhando os tons em cores da marca do SEBRAE com destaque para as seguintes sequências discursivas (SD):

SD01 - Para os negócios, é visão global. Mas a sabedoria popular sempre chamou de "sexto sentido".

SD02 - Na vida e nos negócios, as mulheres não escondem seus diferenciais. Flexíveis, sensíveis, cooperativas, atentas aos detalhes e, ainda, capazes de realizar várias tarefas ao mesmo tempo, elas já não têm mais nada a provar. Mas muito para ensinar.

As SD tratam sobre a incorporação do trabalho feminino no mundo produtivo, mas ao contrário do homem, a mulher, ao se colocar no mundo do trabalho, soma seu trabalho com atividades do lar e às consequências de seus múltiplos papéis - levada a assumir longas jornadas de trabalho por acumular tarefas dentro e fora de casa, numa polivalência funcional ao capital.

Nos termos apresentados pelas SD, o locutor SEBRAE se apoia na sabedoria popular para convencer o(a) leitor(a) que, mesmo optando pelo termo "visão global", confirma como uma asserção consagrada no tempo, o "sexto sentido" e o utiliza como um enunciado de fácil reconhecimento, e seu uso revela as marcas de adesão a sentidos já consolidados na memória discursiva.

Observa-se também que, ao separar "na vida e nos negócios", o SEBRAE faz lembrar que o trabalho feminino está marcado por uma história de confinamento à esfera do lar, numa divisão de tarefas segundo a qual à mulher cabe o cuidado com a casa e os filhos. Apresenta-se de forma disfarçada o reforço ao comportamento masculinizante entre as mulheres de negócios, uma vez que negócios separados da vida exaltam a representação do homem no mundo dos negócios como detentores de prestígio e posições de poder. Contudo, as mulheres estão constantemente expostas a um conflito, que pode ser explicado pela dupla/tripla jornada de tarefas quando gerenciam seus negócios, uma vez que a mulher continua sendo responsável pelas tarefas domésticas.

A imagem ratifica, pois, a incorporação do trabalho feminino no mundo produtivo ${ }^{3}$, mas ao contrário do homem, a mulher, ao se colocar no mundo do trabalho, soma seu trabalho com atividades do lar e às consequências de seus múltiplos papéis - levada a assumir longas jornadas de trabalho por acumular tarefas dentro e fora de casa. Para Kress e Van Leeuwen (2006), existe o caráter ideológico dos elementos visuais na composição de um texto escrito e, segundo eles:

As estruturas visuais não simplesmente reproduzem as estruturas da realidade. Pelo contrário, elas produzem imagens da realidade que está vinculada aos interesses das instituições sociais no interior das quais as imagens são produzidas, circuladas e lidas. Elas são ideológicas. As estruturas visuais nunca são meramente formais: elas têm uma dimensão semântica profundamente importante. (KRESS; VAN LEEUWEN, 2006, p. 47).

As expressões exploração e opressão da mulher têm seu surgimento atrelado ao desenvolvimento das bases materiais da humanidade, através de fatores históricos que marcaram a instituição da exploração, os quais, por sua vez, têm seus fundamentos vinculados ao advento das sociedades de classe, tendo, portanto, uma determinação histórico-econômica. Além disso, as mulheres deveriam ter, entre suas grandes ambições, o casamento ou a constituição familiar. Para elas, o direito à educação era negado, sobrando o trabalho doméstico, e esse "caráter doméstico marca todo o trabalho feminino: a mulher é sempre uma dona-decasa” (PERROT, 2007, p. 114-115). 
$\mathrm{O}$ ato de cuidar, em concomitância com as atividades profissionais, para cumprir normas historicamente criadas e interpretadas, são justificados como inerentes à natureza feminina. Daí porque a necessidade de entender o trabalho feminino, à luz da noção de divisão sexual do trabalho, pois mostra a complexidade da exploração capitalista. Isto ratifica que não se pode entendê-la a partir, apenas, do conceito de classe social, de forma simples, sem agregar a ele a visão social das diferenças de gênero que geram desigualdades entre os sexos, em prejuízo das mulheres, tal como contribuem Heleieth Safiotti, Helena Hirata e Daniele Kergoat.

Amplamente divulgada nos meios midiáticos, a ideo-

[...] as mulheres estão

constantemente expostas a

um conflito, que pode ser

explicado pela dupla/tripla

jornada de tarefas quando

gerenciam seus negócios, uma

vez que a mulher continua

sendo responsável pelas

tarefas domésticas.

logia empreendedora tem ocupado cada vez mais espaço nas políticas de governo e nos modelos estratégicos e educacionais adotados pelo SEBRAE e parceiros institucionais.

Nesse espaço, observou-se a ênfase em capacitações e premiações, que estimulam o desenvolvimento de características pessoais com o objetivo de formar, sobretudo nas mulheres, competências para que as mesmas estejam aptas a criar suas próprias oportunidades em negócios, ao mesmo tempo estas não estariam fadadas à referência do trabalho assalariado, do emprego formal, mas à geração de renda independente.

A solução para o enfrentamento dos obstáculos das mulheres na divisão sexual do trabalho se desloca para a esfera privada, de modo a desenvolver competências empreendedoras. Identifica-se, assim, a sintonia desta ideologia com as teses clássicas do liberalismo, com todas as suas refrações, e que não é explicada pela lei geral da acumulação, pelas contradições do modo de produção capitalista, mas como responsabilidade da própria mulher. A diferença é que no capitalismo contemporâneo, a nova versão liberal - o neoliberalismo - trata de suavizar a tônica do seu discurso, fazendo uso de outros elementos discursivos mais compatíveis, como é o caso do discurso do empreendedorismo feminino.

Contudo, para além de suas novas roupagens discursivas - e entre elas o inconsciente e a ideologia empreendedora - a questão é conhecer o mercado e saber como participar ativamente da economia e, concomitante, saber gerenciar o planejamento individual e familiar. Pelo SEBRAE, há a necessidade de desenvolver comportamentos de "mulher" de negócios de "vencedora"; entendê-los, aprendê-los e colocá-los em prática por meio da inserção no empreendedorismo, além de estimular outras mulheres para que façam o mesmo.

A funcionalidade do empreendedorismo feminino na contemporaneidade está, portanto, na sua capacidade de produzir um apagamento dos conflitos entre capital e trabalho, e das contradições do sistema capitalista de produção, da cultura patriarcal no que se refere ao desemprego, enquanto condição estrutural deste modo de produção. Assim, a aparente transformação de mulheres em empreendedoras implica na ampliação substantiva da polivalência das mesmas, que passam a ser donas do seu negócio e cuidadora da sua família ao mesmo tempo, ratificando que "o indivíduo moderno, a que se qualificava como sujeito de direitos, transmuta-se, assim, num indivíduo-microempresa: Você S/A” (COSTA, 2009, p. 177), favorável à manutenção da ordem do capital.

\section{Considerações finais}

Entre as análises realizadas e as narrativas das mulheres trazidas neste artigo, nota-se que a presença do homem não exime a responsabilidade da mulher provedora no que tange ao compromisso com o seu negócio, pois a mulher tem alguém com quem dividir as despesas domésticas. Mas, também, tem a mulher que não conta com a participação masculina e que, portanto, precisa cuidar sozinha da manutenção da família. Nesse sentido, a união conjugal nem sempre pode ser pensada como suporte financeiro, pois na maioria das narrativas são as mulheres que conseguem aferir maior rendimento, mesmo mergulhadas em condições adversas no acesso a esse mercado, além de conflitos e sofrimentos por sua condição.

Nas discursivas analisadas, confirma-se a prevalência da desigualdade de gênero, assumem a provisão de suas famílias, continuam sendo as principais responsáveis pelo cuidado com os filhos e com as tarefas domésticas. Se de um lado consiste em uma duplicação de afazeres, de outro confere autonomia a essas mulheres, na medida em que permite a descoberta e desenvolvimento de suas capacidades para a superação de problemas individuais e coletivos. 
O discurso trabalho tem entre as características que o constituem a de silenciar o sentido de "exploração" suscitado na relação capitalista. O silenciamento do processo de exploração produz efeitos convenientes à manutenção da ordem e da classe dominante, sobretudo o efeito de liberdade - trabalhador livre -, de autonomia - trabalhador autônomo - e de democratização - trabalho democrático -, entre outros efeitos que sustentam o discurso trabalho na reprodução da ordem vigente.

Amaral (2016) lembra que na sociedade moderna, sob a regência das ideias liberais, o discurso liberal lança mão do discurso trabalho e se fortalece deslocando sentidos sedimentados na memória discursiva do trabalho. Como exemplo tem-se o sentido de "servidão", que desliza para o sentido de "liberdade" nesse espaço discursivo. Com esse estratagema discursivo, os sujeitos são cooptados pelos ideais de "liberdade" e os reproduzem no senso comum: "o trabalho liberta", "o trabalho dignifica a alma", "quem não trabalha não come". O discurso liberal se apropria do discurso trabalho e o converte em meio para atingir seus fins de dominação na ordem burguesa.

Como afirma Mészáros (2006, p. 34), “os obstáculos reais enfrentados pelo trabalho [...] podem ser resumidos em duas palavras: 'flexibilidade' e 'desregulamentação', [...] para toda criatura racional, como a maternidade e a torta de maçã".

Espero ter contribuído ao menos, para suscitar algumas análises a respeito do discurso do trabalho e empreendedorismo feminino e ratificar, nas palavras de Amaral (2005, p. 299) que "[...] toda intencionalidade de atribuir um ponto de chegada a esse processo de reflexão está alicerçada na certeza de que prevalece o movimento de continuidade e ruptura inerente à toda prática social. Estamos do lado daqueles que veem, no fim, o desafio de um começo".

A caminhada continua, na certeza de que "[...] é preciso suportar o que venha a ser pensado, isto é, é preciso "ousar pensar por si mesmo"” (PÊCHEUX, 2009, p. 281). Mesmo que encerrando essas considerações, sigo com a angustiante calmaria de que a dedicação de elaboração de outras análises possíveis torne-se concreta.

\section{Referências}

AMARAL, M. V. B. Discurso e Relações de Trabalho. [2005]. Maceió: Edufal, 2017.

AMARAL, M. V. B. A negação da memória do trabalho no discurso do capital. Resgate: Rev. Interdiscip. Cult., Dossiê discurso e memória, Campinas, v. 24, n. 1[31], p. 37-54, jan./jun. 2016. e-ISSN: 2178-3284.

CHASIN, José. Marx: Estatuto Ontológico e Resolução Metodológica. São Paulo: Boitempo, 1987.

COSTA, A. S. M. Convergências, divergências e silêncios: o discurso contemporâneo sobre o empreendedorismo nas empresas juniores e na mídia de negócios. 2009. Tese (Doutorado) - Escola Brasileira de Administração Pública e de Empresas, Centro de Formação Acadêmica e Pesquisa, 2009.

KRESS, G.; VAN LEEUWEN, T. Reading images: the grammar of visual design. 2. ed. London: Routledge, 2006.

KURZ, Robert. Os últimos combates. Rio de Janeiro, Vozes, 1997.

MARX, K. Capítulo VI, inédito de O capital. São Paulo: Centauro, 2004.

MARX, Karl. A Ideologia Alemã. Lisboa/São Paulo: Presença/Martins Fontes, 1986.

MÉSZÁROS, I. A teoria da alienação em Marx. Tradução de Isa Tavares. São Paulo: Boitempo, 2006.

PÊCHEUX, M. Semântica e discurso: uma crítica à afirmação do óbvio. [1975]. Tradução de Eni Orlandi et al. Campinas: Ed. Unicamp, 2009.

PERROT, M. Escrever a história das mulheres. In: PERROT, M. Minha História das Mulheres. São Paulo: Contexto, 2007.

SOUZA, Cristiane Gomes de. Trabalho, educação e o Plano Nacional de Qualificação do Trabalhador: possibilidades ou limites? 2009. 138f. Dissertação (Mestrado em Serviço Social)-Faculdade de Serviço Social, Programa de Pós-Graduação em Serviço Social, Universidade Federal de Alagoas, Maceió, 2009.

\section{Notas}

1 Verem Souza (2009)

2 Saffioti (2004) alerta, pelo ponto de vista da ordem patriarcal de gênero, a mulher como apaziguadora, relacionada à sensibilidade e inferior em relação ao homem.

3 Kergoat (1996) auxilia no entendimento de que a noção de trabalho doméstico não nega o poder dos movimentos sociais e dos agentes históricos. É a forma concreta que torna o trabalho reprodutivo designado para o grupo das mulheres em uma sociedade assalariada. Ela se coloca como uma dimensão da divisão sexual do trabalho, quando da reestruturação trazida pelo desenvolvimento do sistema capitalista, que separa um espaço/ tempo para trabalhar e ganhar um salário do espaço/tempo do trabalho de reprodução. Ainda em Kergoat (2003), afirma-se que o trabalho de 
reproduçãoé considerado função e território feminino, sendo que a noção de trabalho doméstico está ligada às relações afetivas da família e baseada na "disponibilidade" materna e conjugal das mulheres.

\section{Cristiane Gomes de Souza}

cris.animaconsultoras@gmail.com

Doutora pelo Programa de Pós-graduação em Linguística e Literatura da Universidade Federal de Alagoas (UFAL)

\section{UFAL}

Campus A. C. Simões. Av. Lourival Melo Mota, S/N, Tabuleiro do Martins

Maceió - AL - Brasil

CEP: 57072-970

\section{Agradecimentos}

A minha gratidão às pessoas que foram importantes nessa jornada em análise do discurso, que marcaram a minha vida e contribuíram para a realização da minha tese. Dela fazem parte minhas diferentes relações com diferentes pessoas ao longo da minha formação acadêmica, profissional, produção da pesquisa e do período de escrita.

\section{Agência financiadora}

Não se aplica.

Contribuições das autoras

Não se aplica.
Aprovação por Comitê de Ética e consentimento para participação

Não se aplica.

Consentimento para publicação

Consentimento da autora para publicação.

\section{Conflito de interesses}

Não há conflito de interesses. 